RESEARCH ARTICLE

\title{
This [Black] Woman's Work: Exploring Archival Projects that Embrace the Identity of the Memory Worker
}

\author{
Chaitra Powell ${ }^{1}$, Holly Smith², Shanee' Murrain ${ }^{3}$ and Skyla Hearn ${ }^{4}$ \\ 1 University of North Carolina at Chapel Hill, US \\ 2 Spelman College, US \\ ${ }^{3}$ University of West Georgia, US \\ ${ }^{4}$ DuSable Museum of African American History, US \\ Corresponding author: Holly Smith (hsmith12@spelman.edu)
}

Archivists who work on African American collections are increasingly more aware that traditional sites of African American agency and autonomy are becoming more unstable. The need to capture the perspectives and histories of these institutions is urgent. The challenges become more acute when communities recognize the need to preserve their legacies but do not have the resources or support to make it happen. African American material culture and history remains at risk of co-optation from large institutions and individuals seeking to monetize and profit from collecting Black collections. Endemic in that process is the risk of these institutions controlling the narrative and inadvertently or deliberately erasing the narratives of these diverse communities from that community's perspective. Cultural memory workers focused on African American collections face numerous challenges: the risk of losing the materials or communities themselves; partnering with organizations and administrations with differing, and perhaps conflicting agendas; working on projects with limited or term funding; and the emotional labor of being a person of color in a predominantly white field trying to support communities that can often reflect their own experiences. How can libraries, museums, and archives bring these communities into the world of archives and empower them to protect and share their stories? How can archivists, particularly those of color, find support within their institutions and the archival profession, to accomplish this work of preserving African American cultural heritage? How can archives support genuinely collaborative projects with diverse Black communities without co-opting their stories and collections?

The authors will address these questions in this article, discussing their experiences working with a variety of institutions - predominantly white universities, Black colleges, churches, neighborhoods and families. The authors also include their reflections from their National Conference of African American Librarians panel presentation in August 2017 on these related topics.

Keywords: community archives; African American history; cultural heritage; churches; museums; libraries; activism; African American librarians; African American archivists

During the summer of 2015, in a brightly lit college classroom at UCLA, a group of professional archivists were asked how they would describe their identity in one or two words. The answers included woman, Black, American, Muslim, Christian, human, Southerner, god and more, as one answer inspired another. This dialogue happened during the Developing African American Collections course offered by California Rare Book School, where this article's authors-Chaitra Powell, Holly Smith, Shanee' Murrain, and Skyla Hearn-met. This exercise demonstrated that, even within a group made up primarily of African American women, a wide range of distinct, intersectional identities ${ }^{1}$ inform how we show up personally and

\footnotetext{
' For an overview of the term 'intersectionality,' see Kimberle' Crenshaw's groundbreaking article, 'Demarginalizing the Intersection of Race and Sex: A Black Feminist Critique of Antidiscrimination Doctrine, Feminist Theory, and Antiracist Politics,' University of Chicago Legal Forum 1989, no. 1 (1989): 139-67, http://chicagounbound.uchicago.edu/uclf/vol1989/iss1/8.
} 
professionally. And yet there were many commonalities that united us. Our discussions about work with Black collections revealed that Black people responded authentically to us not only because we are Black, but also because we approached these communities with authenticity, sincerity, and as equal partners. Participants told tales about donors who let down their guard, confessing that our presence assured them that their materials would be valued and appreciated; about others who shared knowing looks with us in a meeting or small talk on the way to the car; and about one supportive individual who wrote a check to endow one of our positions.

In addition to these positive interactions, we also shared frustrations and concerns surrounding working in the archival profession, particularly focusing on Black archives. African American material culture and history remains at risk of co-optation from large institutions and individuals seeking to monetize and profit from these collections. Endemic in that process is the risk of these institutions controlling the narrative and inadvertently or deliberately erasing the stories of these diverse communities from that community's perspective. Black cultural memory workers working with African American collections face numerous challenges, including the risk of losing the materials or communities themselves; partnering with organizations and administrations with differing, and perhaps conflicting, agendas; working on projects with limited or term funding; and the emotional labor of being a person of color in a predominantly white field trying to support communities that can often reflect our own experiences.

In August 2017, we facilitated a session at the National Conference of African American Librarians entitled 'Democratic Histories: Strategies for Engaging African American Communities in the Archival Process.' Our goal was to discuss our work on projects that serve endangered communities, and to facilitate discussion around a related set of issues and concerns. The robust conversations that sprung from this session allowed us to see that our questions about the intersections of identity, history, and the archives are critical to the archival profession. Our experience during this session led to our desire to continue to discuss serious questions such as: How can libraries, museums, and archives connect with communities outside of institutions and empower them to protect and share their stories? How can archivists, particularly archivists of color, find support within their institutions and the archival profession to accomplish this work of preserving African American cultural heritage? How can archives support genuinely collaborative projects with diverse Black communities without co-opting their stories and collections?

The case studies that follow represent a culmination of our personal and professional experiences since that fortuitous meeting in 2015. We chose four principles important to us to map out the sections of this article-advocacy, collaboration, truth, and agency-as a way to frame the discussions. We will discuss our individual experiences with different projects and initiatives in our own voices, as four Black women archivists representing four unique institutions with differing priorities, resources, and agendas. We will discuss our efforts to document Black experiences in ways that eliminate singular narratives and engage scholars, elders, and whole communities in collective, collaborative memory work. We offer our experiences as models and learning opportunities for how individuals and organizations can apply principles of advocacy, collaboration, truth, and agency in forming partnerships within Black communities.

\section{Advocacy}

\section{Chaitra Powell, The Story Does Not End There: Advocating for Archival Intervention in Tuskegee, Alabama}

Chaitra Powell is in her fourth year as the African American Collections and Outreach Archivist in the Southern Historical Collection, a part of University Libraries at the University of North Carolina at Chapel Hill. As a member of the curatorial team, her job includes bringing collections into the archive, curating exhibits, coordinating programs, fundraising, and championing archives in diverse communities. Below she discusses a grant-funded, community-driven archives project to document historically Black Southern Towns.

In the fall of 2014, the Southern Historical Collection (SHC) ${ }^{2}$ embarked on a collaborative archive project with five under-documented, historically Black towns in the American South. Many people are surprised to learn that Tuskegee, Alabama, with its well-known African American heritage, is one of our partners. After all, they have a historically Black college (Tuskegee University), two national parks (Tuskegee Institute and Tuskegee Airmen), and a local history museum (Tuskegee History Museum). All four of these institutions have a demonstrated

\footnotetext{
${ }^{2}$ The Southern Historical Collection is a manuscript collection based in Wilson Library on the campus of the University of North Carolina, Chapel Hill. The Collection was founded in 1930 with a mission to document the American South. Subject strengths include slavery, Civil War, business, politics, and social change. We currently hold over 5,000 collections and over 20 million items.
} 
interest in archives. However, our engagement with some local cultural heritage workers revealed that there is a gap in institutional support for the collecting and telling of important community stories in Tuskegee, Alabama.

On my first short trip to Tuskegee, I met with the local history committee, a collection of representatives from various cultural heritage sites, and learned so much about the town, including the push to preserve and share the stories of Tuskegee's segregated hospital for Black veterans of World War I; the story of Sammy Younge Jr., a slain civil rights worker; the important role that churches and local theaters have played in the community. Everything that I learned could be the basis of an exhibit, an oral history, a collecting initiative, or a community archive. In 2017, the SHC secured funding ${ }^{3}$ from the Andrew W. Mellon Foundation to assemble a team to help us develop a model for meaningful collaboration with communities and design exciting ways for communities to interpret and share their own stories with broader audiences.

Although other towns that we work with have varying levels of resources and enthusiasm about their history, my time in each of these communities yielded similar lessons about what it means to advocate for communities. Among other things, I learned how to leverage my position at UNC to spark interest in preservation, as well as the importance of meeting people where they are and seizing opportunities when community and institutional values are aligned. When I saw the unprocessed collection of papers from Booker T. Washington's National Business League in a local museum's storage area, I exclaimed, 'This is exactly the type of materials we would want in Chapel Hill! You should take steps to preserve and describe it!' But the museum lacked the expertise and personnel to work on the collection.

This encounter led me to write service learning opportunities into a project for which we later received funding from Mellon to complete. Our goal was to help communities get the necessary people-power for well-defined projects. Creating a constellation of resources that can be managed by those best equipped to do so is an important way for the Southern Historical Collection to focus less on extraction of materials and more on keeping communities in control of their intellectual property. And as the costs of storage and staffing rise, we have to rethink the role of a regional archive like the SHC.

Prior to this experience, I only understood advocacy as an attempt to get people with a lot of money and influence to care about people with less money and influence. But archival advocacy also happens when we connect researchers to communities, when we process collections, or when we curate exhibits for diverse audiences. Our involvement signals that that this story belongs alongside all other histories in our care and deserves our support. The impact is magnified with the extraordinary amount of social, scholarly, and financial capital enveloped in the University of North Carolina, Chapel Hill and the Southern Historical Collection. Of course, the ways that we came to have this capital can be off-putting to Black communities, especially those closer to home. Nonetheless, in the archives, we have an opportunity to humble ourselves and use resources and influence to boost the exposure of the histories of local communities.

\section{Collaboration}

\section{Holly Smith, Black Women's Lives in the Archives: Collaborative Approaches in the} Spelman Archives

Holly Smith is the College Archivist at Spelman College. She is passionate about community archives and archival advocacy related to collections for underrepresented groups. Below she discusses a grant-funded program focused on Black women's history in Georgia.

Established in 1881, Spelman College is a historically Black institution that excels in educating a diverse group of young women. It is located in the West End neighborhood of Atlanta and forms part of the Atlanta University Center (AUC) consortium. The AUC has a rich historical legacy, and the West End is overflowing with material culture, historical buildings, and narratives of longtime residents. The neighborhood, however, is shifting, along with Atlanta's population. How are the Black communities then affected by this transitional landscape? How do we preserve historically Black neighborhoods when buildings disappear, landmarks no longer exist, and current inhabitants face being displaced? The physical space, intellectual history, and material culture in these areas risk becoming endangered.

As an archivist, I am pleased to work at an institution where documenting Black women and their families is prioritized. A component of the Women's Resource and Research Center, the College Archives continues Spelman's tradition of documenting the history of the institution and collects in the areas of Black feminism,

\footnotetext{
${ }^{3}$ See the UNC Libraries Press Release about the SHC Mellon Grant ('Building a Model for All Users: Transforming Archive Collections through Community-Driven Archives') on the UNC Library News and Events blog, 'Southern Historical Collection Receives $\$ 877,000$ from Andrew W. Mellon Foundation,' April 25, 2017, http://blogs.lib.unc.edu/news/index.php/2017/04/shc-mellon-foundation/.
} 
social justice, and activism. As a result, we serve a diverse constituency. Being at an HBCU, however, does not mean preservation and community engagement are not without their obstacles. There can be issues with funding, staffing, and the assumption that a Black school will inherently preserve Black cultural heritage 'correctly.' Black institutions can create 'master narratives' of Black history if we privilege certain histories and do not include multiple perspectives that recognize the complexity of individual and institutional memory. It has been paramount for the Archives to build collaborative relationships with diverse stakeholders to preserve Black heritage in Atlanta.

A key outreach program the Archives staff organized in October 2016 was 'Documenting Our Stories: African American Women in Atlanta.' The program, funded by Georgia Humanities, started with a panel discussion with three Black women scholars-Dr. Michelle Hite (English Department, Spelman College), Dr. Sheri Davis-Faulkner (then with West Side Communities Alliance, Georgia Tech), and Dr. Jacqueline Rouse (History Department, Georgia State University). These scholars discussed their own research around Black women, the importance of collecting and preserving archival resources related to women of the African Diaspora, and what their work meant to them personally and professional as women of color. They were joined by colleagues from the Archives Research Center at the Atlanta University Center Robert W. Woodruff Library, the Afro-American Genealogical Society, and StoryCorps Atlanta, who led workshops on basic preservation techniques, African American genealogy, and conducting oral histories. Attendees included members of the Spelman College community as well as the surrounding neighborhood. The event was held at Families First, an organization focused on family support and resources located in the West End. The predecessor to Families First was the Leonard Street Orphans' Home for Colored Girls, founded in 1890 on land that currently forms a part of Spelman's campus. It was particularly poignant to have the program at a neighborhood institution with a historical tie to the campus. Reactions to the program were very positive and affirming. It was great to observe presenters and participants talking after the program and exchanging contact information to stay in touch about future projects and collaborations. Presenters and attendees alike asked about the next time the Archives plans to have a similar program, which was encouraging to hear and demonstrates that such workshops and initiatives can be an ongoing effort.

The project successfully completed its goal of highlighting the importance of Black women's lives in the Archives and sparked an important dialogue about how to preserve individual and family archival collections. It also facilitated connections between Spelman College, the Atlanta University Center, and external community stakeholders. Overall, the program was a good initial step to encourage participants to think about preserving materials in their own home and hopefully feel open and welcomed into academic spaces such as the Spelman Archives for study and research. Next time, we will consider reaching out to other groups in the community, such as churches, mosques, and community service organizations, to expand participation by members of local neighborhoods. There was also a concern that, although the room in which the event was held could fit eighty people, fewer than thirty people showed up. The program would have benefited from expanded marketing and outreach strategies. It would have also been good to consider creating preservation takeaway kits for participants with supplies and other resources, another factor to consider seeking funding and support for at another program down the line. Additionally, some of the participants had trouble navigating the Families First parking lot since there was a security gate through which a guard had to buzz the guests in. We plan next time to either include very specific parking instructions or consider another facility with open parking. Nonetheless, Families First was a great space to have the program, and 'The Documenting Our Experiences' program was a great pilot community-based program for the Archives.

Collaborating with colleagues is also vital to advocate for Black collections and historic landmarks. In 2017, several archivists created the Atlanta Black Archives Alliance (ABAA). As its website states, the ABAA's mission is to 'enhance the visibility of Atlanta's African American archival collections in order to educate and empower diverse communities. ${ }^{\prime 4}$ ABAA meets monthly to develop resources and plan programs. ABAA held a Teaching Atlanta Studies workshop in September 2017 to engage local faculty with African American archives at each partner institution. In February 2018, ABAA hosted an open forum at the Auburn Avenue African American Research Library on African American History and Culture in the heart of downtown Atlanta. The forum facilitated open and frank conversations among archivists, college faculty, activists, and community members about diverse Black collections in Atlanta-area archives. We also discussed significant gaps in the written archival record and the effects of gentrification on neighborhoods and community memory. The forum was a great opportunity to connect individuals invested in African American history and

\footnotetext{
${ }^{4}$ For more information about the Atlanta Black Archives Alliance, visit https://atlantabaa.wordpress.com/author/atlantabaa/.
} 
archives and hopefully foster networking and collaborative projects among diverse institutions. ABAA plans to host these open forums at least quarterly, to provide community updates about the organization's ongoing projects and to engage in continued dialogue about current events and initiatives for preservation of records and neighborhoods. In hosting the 'Documenting Our Experiences' event with community partners and participating in ABAA, the Spelman Archives engaged the surrounding community in conversations about the history and archival memory of Black women locally and internationally, and collaborated on ways to preserve archival treasures in homes and community organizations.

As a Black Southern woman, I see myself in Atlanta's archival and physical landscape. As an ethical archivist, I do not want to co-opt collections and stories for self-promotion or institutional gain. I care about equitable access to archives and the preservation of collective memories, especially related to historically marginalized communities. I want Spelman Archives to play an active role in preserving the endangered knowledge and spaces in Atlanta's ever-shifting landscape.

\section{Truth}

\section{Shanee' Murrain, Black Churches: Contested Stories on Campus (Slave Plantations) and Churches}

Shanee' Murrain is the University Archivist and an Assistant Professor at the University of West Georgia. She is passionate about equity in archival representation, digital collections, information literacy, and community outreach and will discuss the creation of a community archives project focused on outreach to African American area churches.

The University of West Georgia (UWG) boasts many rich traditions, which it has accrued as it has evolved from its founding as the Fourth District Agricultural \& Mechanical School in 1906. In 2016, I joined UWG as the school's first University Archivist, tasked with identifying Carroll County's one-hundred-plus-year-old historic Black churches and providing them with instruction and basic resources for creating and maintaining research-quality archives of their important records, documents, and memorabilia. The community archives project was conceived prior to my arrival at the university and formed a part of the effort to recruit me from my previous position at a historically Black seminary archive. The project was especially appealing because of the opportunity to continue my work coordinating the digitization of religious collections.

Within a few months of managing the primary sources pertaining to the institutional history of UWG, it became apparent that events and folklore in the life of the school would complicate my ability to build relationships with Black churches and convincingly position UWG as a safe collaborator. Simultaneously, I also began to think deeply about being the 'Black Archivist' on a historically white campus and to consider the ways in which controversial stories require a distinctly ethical practice of archival work. When designing a community archives project, archivists need to think about potential risks that institutional histories pose to building relationships with the people we intend to engage and serve. Ethical practice of archival work necessitates that we 1) learn the history of the communities, 2) understand the relationship dynamics (institutional, intergroup, geographic), 3) identify gatekeepers and collaborators to ascertain the needs and manage expectations, and 4) defer to community knowledge.

There are three stories that are crucial to understanding UWG's relationship to the local African American community. The first is related to the Bonner House. Built by Thomas Bonner around 1845, the Bonner House stood as the focal point of the 700-acre cotton plantation on which UWG was developed. As a result, rumors of a slave burial ground have been a part of the university campus folklore for countless years. The Bonner House presently serves as the campus welcome center and features an exhibit about the history of the house, citing 'Abe,' who was born on the plantation in 1841 and lived there for the remainder of the antebellum period.

The second story relates to the historic George Washington Carver High School, which opened in the fall of 1954 as a consolidated high school serving Carroll County's African American students, grades 8-12. In 1955 and 1956, Carver High teacher Jeff Long encouraged senior students to apply to West Georgia College. Their applications for admission were summarily rejected due to their race. In 2005, UWG hosted the three-day Carver High 50th Anniversary and Grand Reunion celebration. University President Dr. Behuruz N. Sethna offered a heartfelt public apology to the class of 1955.

The third story is that of Lillian Williams. She was the first African American to be enrolled at West Georgia College in 1963. The college kept the integration quiet, as Mrs. Williams was a married 33-year-old elementary school teacher who was registered to take English and geography during the summer. The quiet success of Lillian Williams brought forth movement and continued the slow enrollment of African American students, 
but there is also a quiet resentment within the African American community of Carrollton that a college-age student was not selected to integrate the college.

Ms. Carolyn Gray is a seventy-year-old Temple, Georgia native and local historian who led the development of the modular traveling exhibit 'The Carver High Museum and Archives of West Georgia, Inc.,' which uncovers, preserves and shares local Black history pertaining to the public education of African Americans in West Georgia from Emancipation through Integration. My first meeting with Ms. Gray, who would soon become my project co-coordinator, reinforced the importance of doing archival work that does not compromise community members' agency in telling their stories. We talked about preservation and honesty, including telling the truth about community relations with the university. When discussing Carroll County school integration, Ms. Gray frankly said, 'If they wanted a better history 50 years later they should've acted right back then.' Ms. Gray is a community gatekeeper whose previous work documenting the history of Black churches and schools in West Georgia has laid the foundation for our community archives project. Because of her introductions, I presented a workshop to Haralson County Aiding and Building Convention on how to best preserve the history of the convention's six Baptist Churches and formally announced the project through a multimedia public relations campaign on Facebook and in a local newspaper, a WLBB radio interview, other local media, and mailings to local Black churches.

Working within the legacy of UWG, the project calls for a service-based reciprocal relationship with church members and a shared stake in the project to overcome the historical legacy of white institutions exploiting or ignoring Black history, especially because the conceptualization of the project could be perceived as yet another rejection by UWG, which did not want them enrolled then and does not want their archives now. Therefore, this project is based on the post-custodial theory of archives and recognizes church members as the authority on the church and the needs for documenting its history. How that history is told, through years of written and published documentation, oral testimonies and artifacts, is partially informed by both the archivist and the archive. The records creators, in this case the churches, will retain their records instead of donating them to UWG. Typically, archivists do not tell the story of Black Church life; the records and the communities they come from do. The Black Church is the expert on Black Church life. In describing the project to prospective congregations, we emphasize a service-based reciprocal relationship with members of the church having a shared stake, noting that as archivist of the University of West Georgia, I bring expertise as trained librarian/public historian, but recognize and defer to church members as the ultimate authority on the church.

\section{Agency}

\section{Skyla Hearn, The Ultimate Legacy Holders: Defining the Terms by Which We Live, Love and Labor}

Skyla Hearn serves as Chief Archivist and Special Collections Librarian for the DuSable Museum of African American History in Chicago. As an activist archivist, she works with cultural heritage, arts, education, and community organizations and institutions throughout the state and will discuss a community's successful grassroots efforts to create an archive and museum.

What does it mean to grow from an organic, grassroots passion project into a nationally recognized organization? This is a quandary that needs to be faced with balanced astute objectivity and compassion when considering how a small endeavor becomes a massive undertaking that thrives despite adversarial circumstances.

In the early 1960s, Margaret and Charles Burroughs decided to embark on a revolutionary action, one that had not yet gained traction in most second-space ${ }^{5}$ communities, especially the Black community: to establish a museum focused on the people and continent of Africa inside of their south-side home, located in the heart of the Bronzeville community in Chicago. Prior to establishing this museum, which the Burroughs called the Ebony Museum of Negro History, ${ }^{6}$ Margaret Burroughs had been an activist, artist and high school art teacher at DuSable High School, one of the few schools Blacks comfortably attended. Concerned that the school's academic offerings featured limited information about the contemporary experience of American Blacks, Burroughs decided to incorporate Black history, art, and culture into her curriculum. Her home

\footnotetext{
${ }^{5}$ I first became familiar with the phrase 'second space' through my introduction to the work of archivists Tamar EvangelistaDougherty and Bergis Jules with the Black Metropolis Research Consortium (BMRC). The terminology 'second space' refers to community-based organizations, individuals and holders of non-traditional subject matter and formats pertaining to African Americans. In this instance, 'second space' refers to grassroots undertakings managed by members of the community they serve.

${ }^{6}$ The DuSable Museum of African American History began as the Ebony Museum and then was named the Museum of Negro History and Art.
} 
museum provided supplementary exposure for her students, who were able to view a wide range of artifacts and participate in more in-depth conversations and lectures there.

The Burroughs received a great deal of support from members of the community, who donated objects and attended lectures. This outpouring of support resulted in the acquisition of a larger space to establish the museum. By the early 1970s, friends and colleagues eagerly joined Margaret and Charles' effort to further develop the museum into an institution to serve the needs of the community. At its inception, the museum consisted of an administrative staff that either concurrently held dual positions or left their jobs to fully dedicate themselves to the establishment of the DuSable Museum of African American History. The small staff, comprised of quasi-museum professionals, set out to develop bylaws, create a Board of Directors, and appoint staff positions, all while acquiring and receiving art, artifacts, and archives and facilitating public programs and events. The group diligently documented their enterprise, providing proof of the efforts and contributions of Africans/Black Americans/Blacks of the Diaspora. Their dedicated labor achieved unprecedented success, which created the model for the development of other national museums of Black history and art.

Advocacy and sustainability, along with focus on the relationship to the community, remain at the apex of the ideology of the museum, an institutionalized organization produced from a labor of love.

\section{Conclusion: How Does Being a Woman, Black, and an Archivist Impact This Work?}

The diverse projects and initiatives described above emerge out of various cultural heritage agencies, each one using a different strategy for outreach and collaboration with local African American communities. Our vignettes touch on several overarching themes, including the deliberate erasure of Black history, the negative impacts of desegregation, and the long history of racism in the archives, as well as the ways in which we, as Black women archivists, work to combat these challenges. In the process of writing this article, we were fortified by seeing similar patterns across our experiences and our institutions. Shanee' and Chaitra could see the ways in which addressing institutional legacies at predominantly white institutions has been foundational to successful collaboration with Black communities. Holly and Skyla can attest to the importance of working to ensure that Black communities do not privilege certain narratives at the expense of others and the challenges presented by working within small and often under-funded departments. As Chaitra's predecessor in the Southern Historical Collection, Holly shared important advice about navigating the bureaucracy, which sped up Chaitra's adaptation to the environment and empowered her to find new ways to engage Black communities. We serve as peer mentors to each other as well as colleagues, providing emotional and professional support in sharing similar experiences as well as talking through different challenges. This speaks to the point we outlined in the introduction, the importance of finding supportive colleagues and networks, particularly as women of color working in communities we feel personally invested in. We feel affirmed in 'showing up' as our authentic selves, with our diverse identities, and seeing that as an asset to our profession, not a liability.

Each project or initiative outlined had numerous positive results: the creation of archival institutions, the forging of new partnerships, the acquisition of collections, and the implementation of outreach programs to engage new communities and identify new stakeholders. However, since this work is ongoing, we hesitate to stamp these projects as simply 'successful,' as that term can be very layered. Does success indicate a completion, a finality? For example, the public programs that Holly and Shanee' executed were successful in that they fulfilled the initial project outcomes. Yet the long-term preservation of these communities and collections is ongoing, and methodologies and ideas have to be revisited and shifted as necessary. In a presentation at the 2018 Society of North Carolina Archives conference, Chaitra highlighted the importance of 'slow archives' in regards to the grant-funded Black Towns project. She noted that the SHC staff sought to take a step back from the acquisition of collections and perhaps focus more on training and support for community members to steward their own materials. This approach allows for conscious reassessment and a refocusing of project goals and initiatives, and it is a critical step in determining steps for long term, equitable community partnerships. Short-term successes, like a well-attended workshop, can help establish goals and priorities for long-term relationship building and project sustainability. But they comprise only a part of the final objective.

In this essay, we have highlighted programs and initiatives that function as models for creating collaborative relationships with diverse African American communities. These programs also demonstrate strategies for providing equitable and just access to collections. As socially responsible archivists, we seek to affirm the validity of all memories and stories and not privilege one person's story over another. We assert that all memories and stories are valid. 
We hope other organizations can incorporate the strategies of authentic coalition building that we have described to capture diverse memories and stories and develop effective outreach and advocacy tools. These projects have taught us several lessons.

1. If Black history is left in the hands of the founders of most mainstream collections, we will always be piecing together our stories through a fractured lens. In 2018, it is important to recognize the work of professional archivists with diverse backgrounds who do their work with great passion and skill.

2. Black women archivists stand at an intersection between the institutions and communities that we represent. We inhabit intersectional identities and bring diverse experiences to our careers. We advocate for historically marginalized communities, and we support one another dealing with professional macroaggressions, institutional roadblocks, and recognizing the emotional labor we expend as Black women in memory work.

3. We want to be good stewards and serve as a bridge between communities and institutions, and thankfully we have been supported at our respective organizations overall. We also want to be careful not to feel co-opted or serve as a representative in any way as the sole Black person speaking for an organization, or to allow African American communities to serve as props or have stories co-opted and used to further an institution's agenda.

4. It takes time to build genuine, equitably collaborative relationships. That can include stepping back to reevaluate a project's original goals and redirect resources, energy, and intentions as needed.

As Black women memory workers focused on equity, justice and access, we do not see ourselves as passive keepers of 'dead' historical records. We play an active role in shaping history and memory through our actions and choices (things we choose to document and things we overlook), and we remember that we are one of many stewards with a passion for African American history and culture. Our professional practice demonstrates caring for people as evidence of capacity to care for materials. Community partners bring wisdom, knowledge, and expertise of their neighborhoods, traditions, and memory. They do not need to see their collections and stories co-opted by any institution. Whether we are in the field building new relationships with marginalized communities or flagging important details in a biographical note, our work is improving the research landscape for future generations and fighting to preserve endangered knowledge and spaces in partnership with diverse communities.

\section{Competing Interests}

The authors have no competing interests to declare.

How to cite this article: Powell, Chaitra, Holly Smith, Shanee' Murrain and Skyla Hearn. 2018. This [Black] Woman's Work: Exploring Archival Projects that Embrace the Identity of the Memory Worker. KULA: knowledge creation, dissemination, and preservation studies 2(1): 5. DOI: https://doi.org/10.5334/kula.25

Submitted: 20 February 2018 Accepted: 28 August $2018 \quad$ Published: 29 November 2018

Copyright: (c) 2018 The Author(s). This is an open-access article distributed under the terms of the Creative Commons Attribution 4.0 International License (CC-BY 4.0), which permits unrestricted use, distribution, and reproduction in any medium, provided the original author and source are credited. See http://creativecommons.org/ licenses/by/4.0/

$\mathrm{u}[\quad$ KULA: knowledge creation, dissemination, and preservation studies is a peer-reviewed open access journal published by Ubiquity Press. 